\title{
Efficiency of Green Supply Chain in the presence of non-discretionary and undesirable factors, using Data Envelopment Analysis
}

\section{Mehdi Shoja ${ }^{a}$}

E-mail: mmsh.bim@gmail.com

\section{Farhad Hosseinzadeh Lotfi ${ }^{b}$}

E-mail: farhad@hosseinzadeh.ir

\section{Amir Gholam Abri ${ }^{\mathrm{c}}$}

E-mail: amirgholamabri@gmail.com

\section{Alireza Rashidi Komijan ${ }^{c}$ (D)}

E-mail: rashidi@azad.ac.ir

\footnotetext{
${ }^{a}$ Roodehen Branch, Islamic Azad University

Address: No 4, Shahid Ahmadi Alley, Valiasr Town, Firoozkooh, Tehran 3981838183, Iran

${ }^{\mathrm{b}}$ Science and Research Branch, Islamic Azad University

Address: Shohada Hesarak Blv, University Square, End of Shahid Sattari Highway, Tehran 1477893855 , Iran

${ }^{\mathrm{c}}$ Firoozkooh Branch, Islamic Azad University

Address: First of Valiasr Town, 45 Meters Street, Firoozkooh, Tehran 3981838381, Iran
}

\begin{abstract}
A new approach that has dominated the production operations management field in recent years is supply chain management. A supply chain includes all the facilities, tasks and activities involved in manufacturing a product from suppliers to customers. Its various elements are planning, supply and
\end{abstract}

\footnotetext{
${ }^{*}$ Corresponding author
} 
demand management, procurement of raw materials, production scheduling, distribution and delivery of products to the customer. Special structures in the supply chain have been less studied in previous research. In this paper, the supply chain and its performance evaluation are examined in the presence of non-discretionary, undesirable and negative data. For this purpose, another model of the network DEA is presented which evaluates performance of the chain in the presence of non-discretionary inputs and outputs, undesirable outputs and negative outputs even in its internal structure. The efficiency of the chain stages is also calculated using a dual model. Subsequently, 42 cement companies listed on the Tehran stock exchange were evaluated, each of which has a chain of four stages including suppliers, manufacturers, distributors and customers. Based on the implementation of the model, six companies were found to be efficient and the rest were introduced as inefficient. Moreover, 25 cement companies in the Supplier sector, 18 companies in the manufacturing sector, seven companies in the distribution sector and finally 17 companies in the customer service sector were found to be efficient.

Key words: supply chain efficiency; cement industry; network DEA; non-discretionary factors; undesirable outputs; negative data.

Citation: Shoja M., Lotfi F.H., Abri A.G., Komijan A.R. (2021) Efficiency of Green Supply Chain in the presence of non-discretionary and undesirable factors, using Data Envelopment Analysis. Business Informatics, vol. 15, no 3, pp. 78-96. DOI: 10.17323/2587-814X.2021.3.78.96

\section{Introduction}

I n recent years, a relatively suitable approach has been presented in the intellectual, cultural and social fields on performance and productivity evaluation. In fact, today productivity is not strange for the thinking and beliefs of the community. Different applications of the supply chain in various sciences have attracted many researchers. The network supply chain consists of four parts: supplier, manufacturer, distributor and customer. The supply chain structure varies in terms of size and complexity, from a simple chain that represents independent decision-making, to the behaviors and interactions of complex companies. Therefore, proper supply chain performance evaluation is necessary to consider the network characteristics of the chain and its interactions. Generally, the larger and more complex the supply chain is, the more difficult it will be to evaluate.

Among the evaluation methods, data envelopment analysis (DEA) is widely used to evaluate the relative performance of a set of pro- duction processes called decision-making units (DMUs). This non-parametric method evaluates DMUs by presenting different models that produce multiple outputs using multiple inputs. DEA is a very important method in supply chain management literature.

Classical DEA models do not have any theory regarding the intermediate activities of DMUs and consider them as a black box, so that just the inputs consumed and the final outputs produced are considered in calculating efficiency. This view, which does not consider intermediate activities and products of the supply chain, is suitable for a simple production process, however it doesn't have proper application in a complex network system.

To identify inefficiencies and their causes in the intermediate parts, many researchers have tried to reject the black box model and consider its internal structure in DEA models. These models are called 'network DEA' in the literature. The supply chain is one of the most important and most practical states of network DEA. Planned production of raw materials, designing 
and producing appropriate products, optimal distribution and delivery, and ultimately serving customers and their satisfaction in the form of supply chain management, are of great interest. In supply chain management, all efficiency measurements seek to achieve two ultimate goals of reducing costs and increasing profits.

The important thing to consider in these situations is that, sometimes changing some inputs and outputs of the supply chain are not entirely available to the manager. These are called nondiscretionary or partly-discretionary factors. In addition to non-discretionary factors, in some cases, there may be undesirable indicators within middle activities of the supply chain. Dealing with these indicators in classical DEA models has been discussed, however non-discretionary inputs and outputs, undesirable outputs and negative outputs are less discussed in previous studies performed on supply chains. Therefore, in this study, we have tried to examine these conditions in the full supply chain. In other words, the aim of this paper, is to present a model based on DEA, with a network structure to evaluate the total efficiency and performance of supply chain steps in the presence of non-discretionary inputs and outputs, undesirable and negative outputs.

As we know, recently the application of data envelopment analysis has attracted a lot of attention in various sciences, and many studies have been carried out in the field of data envelopment analysis with a network structure, all of which attempts to analyze different states of a network. In this regard, one of the first studies was presented about twenty years ago by Färe and Grosskopf [1, 2]. They considered the production possibility set with original standard principles in the variable returns-to-scale scheme for the general structure of a network, and then created the production possibility set of the supply chain by combining the sets of production possibilities for its internal parts. Tone and Tsutsui [3] showed that these assumptions need more discussion. For example, if we consider labor, raw materials and capital as inputs, the same decrease in all of them may not be possible. Therefore, they suggested a network DEA model that used a slack-based measurement method to evaluate the efficiency of different parts.

Xu et al. [4] evaluated the supply chain performance of furniture manufacturing industries in southwestern China by presenting a rough DEA model. They identified the main uncertainty factors that affect the evaluation process, and then, these cases formed a model and were analyzed using rough DEA (RDEA) models.

As we know, a proper measurement of the supply chain efficiency must take into account both the network properties of the chain and the relationship among supplier, manufacturer, distributor, and customer. Taking into account these considerations, Saranja and Moser [5], and Chen and Yan [6] presented various models with different supply chain structures.

Azadeh and Alem [7] presented three models of supplier selection in the supply chain in certainty, uncertainty and probabilistic circumstances. These models include data envelopment analysis (DEA), fuzzy data envelopment analysis (FDEA), and chance constrained data envelopment analysis (CCDEA). Babazadeh et al. [8] designed a network supply chain for organizing a biodiesel fuel type in Iran using a combined model of data envelopment analysis and mathematical programming model. Badiezadeh et al. [9] discussed the supply chain in the presence of big data and undesirable outputs. Boudaghi and Saen [10] provided a combined model of data envelopment analysis and discriminant analysis (DEA-DA) to predict group membership of suppliers in the sustainable supply chain. The proposed model could predict this, considering the nature of factors, such as inputs, outputs and performance of each supplier. Fathi and Saen [11] presented a model of bidirectional network DEA in assessing the sustainability of distribution supply chains, to rank Iran's transportation companies and propose improvement solutions. Goodarzi and Saen [12] also considered unde- 
sirable outputs by developing the SBM model in network DEA. Grigoroudis et al. [13] presented a recursive DEA algorithm (RDEA) that introduces a different method to design a supply chain network. Huang [14] examined the tourism industry in the framework of supply chain and calculated the efficiency of each sector as well as overall efficiency. One of the characteristics that distinguishes this research from other research is the division of model inputs into variable and semi-variables and using it in mathematical programming. Izadikhah and Saen [15] evaluated the stability of supply chains with a two-stage model in the presence of negative data. Izadikhah et al. [16] developed conventional DEA models to a method to assess the sustainability of suppliers in the presence of internal and fuzzy data. Kalantari and Saen [17] examined the sustainability of supply chains with a model of reverse dynamic network DEA. Khodakarami et al. [18] analyzed the evaluation of 27 Iranian companies in the context of supply chain management sustainability based on the development of a two-stage model. Mirhedayatian et al. [19] assessed green supply chain management in the presence of undesirable outputs and fuzzy data. Sarah and Khalili-Damghani [20] evaluated the natural gas supply chain with the fuzzy type-II De-Novo program for allocating resources and setting the target in network DEA. Shafiee et al. [21] used a combination of network DEA and balanced scorecard approach to evaluate supply chain performance. In this method, the combination of Balanced Scorecard (BSC) and DEMATEL method was used for network structure. Then the structure of this network was expressed in the form of DEA, and was evaluated in this structure. Tajbakhsh and Hassini [22] provided a method for evaluating the sustainability of supply chain networks. Their focus was on three issues: to maximize economic return, to minimize environmental impact and to achieve social expectations. They applied the proposed model to evaluate two case studies, one in the manufacturing sector and the other in the banking sector.
Tavana et al. [23] presented a two-stage methodology for assessing the performance of the three-part supply chain, including supplier, manufacturer and distributor.

Tavana et al. [24] evaluated the supply chain performance by providing a network epsilon based measure (NEBM) and emphasized the radial and non-radial (hybrid) simultaneous changes in inputs and outputs in the network. Tavassoli and Saen [25] evaluated the prediction of membership in a sustainable supplier group using the DEA and Discriminant Analysis. Yousefi et al. [26] presented improvement ways and optimal solutions, using a combination model of goal programming and data envelopment analysis with network structure. Zhai et al. [27] measured the efficiency of energy supply chains with business plan, by presenting a twostage frontier-shift DEA model.

In this research, the application of data envelopment analysis is examined for evaluating supply chain management in the presence of nondiscretionary, undesirable and negative data. A model is presented with the inclusion of the above particular circumstances, according to which the performance of listed cement companies in the stock exchange is calculated. Therefore, the innovations of this research are as follows:

- development of network models in the data envelopment analysis with undesirable intermediate and final outputs, and negative outputs;

- development of network models in data envelopment analysis with non-discretionary and partly-discretionary factors;

- application of the models so developed in the cement industry, taking into account the specific conditions of the indicators.

The rest of this paper includes the following sections: reviewing basic concepts, presenting a suitable model in the presence of non-discretionary, undesirable and negative indicators, presenting a case study in the field of the cement industry with the structure of the proposed model. Finally, the results are investigated. 


\section{Basic concepts}

Suppose that there are $n$ decision-making units so that $Y_{j}=\left(y_{1 j}, \ldots, y_{s j}\right)^{t}, X_{j}=\left(x_{1 j}, \ldots, x_{m j}\right)^{t}$ are $D M U_{j}$ input and output vectors respecti-vely, and $X_{j} \geq 0, X_{j} \neq 0, Y_{j} \geq 0, Y_{j} \neq 0$.

By accepting the principles of Inclusion of observations, fixed-scale returns, convexity, feasibility, and the minimum of interpolation, the Production Possibility Set is as follows:

$$
\begin{gathered}
T_{c}=\left\{\left(\begin{array}{l}
X \\
Y
\end{array}\right) \mid X \geq \sum_{j=1}^{n} \lambda_{j} X_{j} ;\right. \\
\left.Y \leq \sum_{j=1}^{n} \lambda_{j} Y_{j} ; \lambda_{j} \geq 0 ; j=1,2, \ldots, n\right\} .
\end{gathered}
$$

By eliminating the assumption of constant returns-to-scale from the above assumptions, the Production Possibility Set turns into below for which its returns-to-scale is variable:

$$
\begin{gathered}
T_{v}=\left\{\left(\begin{array}{l}
X \\
Y
\end{array}\right) \mid X \geq \sum_{j=1}^{n} \lambda_{j} X_{j} ; Y \leq \sum_{j=1}^{n} \lambda_{j} Y_{j} ;\right. \\
\left.\sum_{j=1}^{n} \lambda_{j}=1 ; \lambda_{j} \geq 0 ; j=1,2, \ldots, n\right\} .
\end{gathered}
$$

The following input-oriented model, should be solved in order to evaluate $D M U_{o}$ :

$$
\begin{gathered}
\sum_{j=1}^{n} \lambda_{j} x_{i j} \leq \theta x_{i o}, i=1,2, \ldots, m ; \\
\sum_{j=1}^{n} \lambda_{j} y_{r j} i y_{r o}, r=1,2, \ldots, s ; \\
\sum_{j=1}^{n} \lambda_{j}=1 ; \lambda_{j} \geq 0, j=1,2, \ldots, n .
\end{gathered}
$$

Model (3) that is called an input-oriented BCC model, is introduced by Banker, Charnes and Cooper [28].

It's clear that $D M U_{o}$ is Pareto efficient if and only if $\theta^{*}=1$ and the value of all auxiliary variables is zero, in each optimal solution of the model (3).

Definition 1: Let $(X, Y)$ be input and output vector corresponding any $D M U .\left(X^{\prime}, Y^{\prime}\right)$ is the transformed form of this unit with respect to constant values of $\alpha_{i}$ and $i=1,2, \ldots, m$ and $\beta_{r}$, $r=1,2, \ldots, s$, if:

$$
\begin{aligned}
& x_{i j}^{\prime}=x_{i j}+\alpha_{i}, \quad i=1,2, \ldots, m, j=1,2, \ldots, n ; \\
& y_{r j}^{\prime}=y_{r j}+\beta_{r}, \quad r=1,2, \ldots, s, j=1,2, \ldots, n .
\end{aligned}
$$

Definition 2: A DEA model is called stable to transmission if the efficiency of the $D M U_{s}$ (the value of model objective function) when transforming inputs and outputs of them is not changed.

Theorem 1: The input-oriented BCC model is stable with respect to the output transmission [29].

The above theorem indicates that if the outputs are transmitted in the input-oriented BCC model, its objective function or efficiency score will not change.

A centralized control model was developed by Chen and Yan [6] to evaluate the performance of the two-stage supply chain. For simplicity, they assumed a supplier- manufacturer chain, as in Figure 1.

Where, $S$ is supplier, $M_{1}$ and $M_{2}$ represent first and second manufacturers, respectively. $X=\left(x_{1}, \ldots, x_{m}\right)$ is input vector of supplier $S$ and $Y^{1}=\left(y_{1}^{1}, \ldots, y_{k}^{1}\right), \quad Y^{2}=\left(y_{1}^{2}, \ldots, y_{k^{\prime}}^{2}\right) \quad$ are output vectors of it which are also input vectors of manufacturers $M_{1}$ and $M_{2} . Z^{1}=\left(z_{1}^{1}, \ldots, z_{s}^{1}\right)$ and $Z^{2}=\left(z_{1}^{2}, \ldots, z_{s^{\prime}}^{2}\right)$ are output vectors corresponding to $M_{1}$ and $M_{2}$ respectively.

SSuppose that $D M U_{1}, D M U_{2}, \ldots, D M U_{n}$, are decision-making units corresponding to the 1 -st chain, 2-nd chain, ..., $n$-th chain, respectively. The model presented by Chen and Yan for measuring overall efficiency of corresponding chain of $D M U_{o}$ with constant returns to scale assumption is as follows:

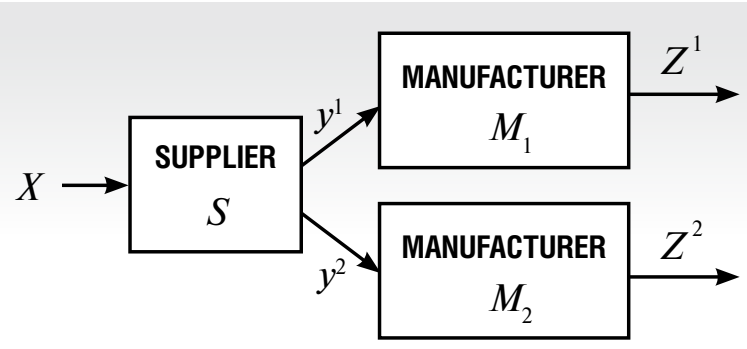

Fig. 1. Two-stage supply chain 


$$
\begin{aligned}
& \min _{n}^{n} \theta ; \\
& \sum_{j=1}^{n} \lambda_{j}^{1} x_{i j} \leq \theta x_{i o}, i=1,2, \ldots, m ; \\
& \sum_{j=1}^{n} \lambda_{j}^{1} y_{t j}^{1} \geq \sum_{j=1}^{n} \lambda_{j}^{2} y_{c j}^{1}, t=1,2, \ldots, k ; \\
& \sum_{j=1}^{n} \lambda_{j}^{1} y_{t^{\prime}}^{2} \geq \sum_{j=1}^{n} \lambda_{j}^{3} y_{c^{\prime} j}^{2}, t^{\prime}=1,2, \ldots, k^{\prime} ; \\
& \sum_{j=1}^{n} \lambda_{j}^{2} Z_{r j}^{1} \geq Z_{r o}^{1}, r=1,2, \ldots, s ; \\
& \sum_{j=1}^{n} \lambda_{j}^{3} Z_{r^{\prime} j}^{2} \geq Z_{r^{\prime} o}^{2}, r^{\prime}=1,2, \ldots, s^{\prime} ; \\
& \lambda_{j}^{1}, \lambda_{j}^{2}, \lambda_{j}^{3} \geq 0, j=1,2, \ldots, n .
\end{aligned}
$$

The main discussion of model (5) is how to evaluate the supply chain with regard to intermediate products in DEA models. Using the above model, the supply chain being evaluated is efficient if and only if $\theta^{*}=1$.

\section{Methodology}

Examining supply chain performance in industries is considered a sample of multi-stage and network decision-making units that should include intermediate products and the relationship between activities within the various parts of its system. In these systems, the outputs of a stage (process) are considered as inputs of the next stage, which is called intermediate data $[30,31]$. Moreover, in each stage there may be independent inputs for that stage which should be considered. Managers must try to identify the factors affecting supply chain performance by developing appropriate methods, use them to measure the overall efficiency and performance of various sectors. Some of these effective factors are nondiscretionary inputs and outputs, undesirable outputs and negative outputs that need to be identified and considered in developing the model for evaluation. In this research, the supply chain of the cement industry is evalu-ated in the presence of non-discretionary, undesirable and negative factors. It will have the following structure:

In the above chain:

$\downarrow S_{1}, S_{2}, S_{3}$ and $S_{4}$ represent supplier, manufacturer, distributer and costumer, respectively;

$$
\downarrow X_{j}^{f}=\left(\begin{array}{l}
x_{i j}^{f}, i \in D^{f} \\
x_{i j}^{f}, i \in N D^{f}
\end{array}\right) \text { for } f=1,2,3,4 \text {, is }
$$

input vector of $D M U_{j}$ including discretionary and non-discretionary inputs to stage $S_{f}$;

$$
\downarrow Z_{j}^{k_{1}, k_{1}+1}=\left(\begin{array}{ll}
z_{l j}^{k_{1}, k_{1}+1}, & l \in D^{k_{1}, k_{1}+1} \\
z_{l j}^{k_{1}, k_{1}+1}, & l \in N D^{k_{1}, k_{1}+1}
\end{array}\right) \text { for } k_{1}=1,2,3
$$

are intermediate data from stage $S_{k_{1}}$ to stage $S_{k_{1}+1}$ of $j$-th unit which includes discretionary and non-discretionary data, or in other words represents the output vector of stage $S_{k_{1}}$ of $j$-th unit, including discretionary and non-discretionary outputs which also are the input of stage $S_{k_{1}+1}$ for that unit;

- $Y^{k_{2}}=\left(y_{r j}{ }^{k_{2}} ; r \in R^{k_{2}}\right)$ for $k_{2}=1,2,3$ are the undesirable output of stage $S_{k_{2}}$;

- $Y=\left(y_{1}, y_{2}, \ldots, y_{s}\right)$ is the output vector of stage $S_{4}$;

- $D^{f}$ and $N D^{f}$ for $f=1,2,3,4$ are set of discretionary and non-discretionary input indices, respectively;

- $D^{k_{1}, k_{1}+1}$ and $N D^{k_{1}, k_{1}+1}$ for $k_{1}=1,2,3$ are a set of discretionary and non-discretionary indicators indices, respectively;

- $R^{k_{2}}$ for $k_{2}=1,2,3$ show a set of undesirable output indices for level $S_{k_{2}}$.

Consider $n$ identical supply chains similar to chains in Figure 2 that are called n decision-

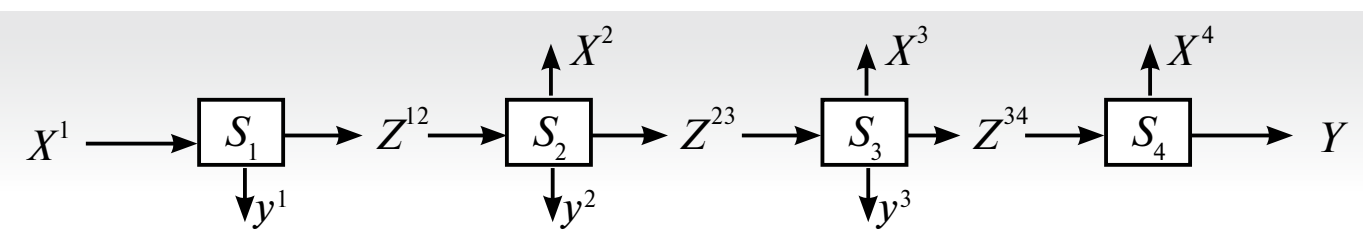

Fig. 2. Four-stage supply chain 
making units in the data envelopment analysis literature which are denoted as $D M U_{1}$, $D M U_{2}, \ldots, D M U_{n}$. A network DEA model with series structure is required to calculate their performance. The BCC model can't specifically identify the function of the corresponding black box of the supply chain in Figure 2, because it only takes into account the inputs and outputs of the supply chain and ignores the intermediate products resulting from supply chain processes and factors affecting its performance. Therefore, a suitable model is required to be developed for evaluating the above supply chain.

By accepting the principles of Inclusion of observations, convexity, feasibility (except for non-discretionary intermediate products) and the minimum of interpolation, PPS for stages and total PPS for the supply chain of Figure 2 are as follows:

$$
\begin{aligned}
& \left.T_{v}^{1}=\left\{\begin{array}{l}
\left(\begin{array}{l}
X^{1 D} \\
X^{1 N D}
\end{array}\right) \\
Z^{12 D} \\
Z^{12 N D} \lambda_{j=1}^{n} \lambda_{j}^{1} x_{j}^{1 D} \leq X^{1 D} ; \sum_{j=1}^{n} \lambda_{j}^{1} x_{j}^{1 N D} \leq X^{1 N D} ; \\
Y^{1}
\end{array}\right) \begin{array}{l}
\sum_{j=1}^{n} \lambda_{j}^{1} z_{j}^{12 D} \lambda_{j}^{1} z_{j}^{12 N D}=Z^{12 D} \\
\\
\sum_{j=1}^{n} \lambda_{j}^{1} y_{j}^{1} \leq Y^{1} ; \sum_{j=1}^{n} \lambda_{j}^{1}=1 ; \lambda^{1} \geq 0
\end{array}\right\} \\
& T_{v}^{2}=\left\{\begin{array}{l|l}
\left(\begin{array}{l}
X^{2 D} \\
X^{2 N D}
\end{array}\right. & \sum_{j=1}^{n} \lambda_{j}^{2} x_{j}^{2 D} \leq X^{2 D} ; \sum_{j=1}^{n} \lambda_{j}^{2} x_{j}^{2 N D} \leq X^{2 N D} ; \\
Z^{12 D} & \sum_{j=1}^{n} \lambda_{j}^{2} z_{j}^{12 D} \leq Z^{12 D} ; \\
Z^{12 N D} & ; \\
Z^{23 D} & \sum_{j=1}^{n} \lambda_{j}^{2} z_{j}^{23 D} \geq Z^{23 D} ; \\
Z^{23 N D} & \sum_{j=1}^{n} \lambda_{j}^{2} z_{j}^{12 N D}=Z^{12 N D} ; \\
Y^{2} & \sum_{j=1}^{n} \lambda_{j}^{2} z_{j}^{23 N D}=Z^{23 N D} ; \\
& \sum_{j=1}^{n} \lambda_{j}^{2} y_{j}^{2} \leq Y^{2} ; \\
\sum_{j=1}^{n} \lambda_{j}^{2}=1 ; \lambda^{2} \geq 0
\end{array}\right\} ;
\end{aligned}
$$

$$
\begin{aligned}
& T_{v}^{3}=\left\{\begin{array}{l}
\left(\begin{array}{l}
X^{3 D} \\
X^{3 N D} \\
Z^{23 D} \\
Z^{23 N D} \\
Z^{34 D} \\
Z^{34 N D} \\
Y^{3}
\end{array}\right) ; \sum_{j=1}^{n} \lambda_{j}^{3} x_{j}^{3 D} \lambda_{j}^{3} z_{j}^{23 D} \leq X^{3 D} ; \sum_{j=1}^{n} z_{j}^{23 D} \lambda_{j}^{3} x_{j}^{3 N D} \sum_{j=1}^{n} \lambda_{j}^{3} z_{j}^{34 D} \geq Z^{23 N D} ; \sum_{j=1}^{n} \lambda_{j}^{3} z_{j}^{34 D D} ; \\
\sum_{j=1}^{n} \lambda_{j}^{3} y_{j}^{3} \leq Y^{3} ; \sum_{j=1}^{n} \lambda_{j}^{3}=1, \lambda^{3} \geq 0
\end{array}\right\} ; \\
& \left.T_{v}^{4}=\left\{\begin{array}{l}
X^{4 D} \\
X^{4 N D} \\
Z^{34 D} \\
Z^{34 N D} \\
Y
\end{array}\right) \begin{array}{l}
\sum_{j=1}^{n} \lambda_{j}^{4} x_{j}^{4 D} \leq X^{4 D}, \quad \sum_{j=1}^{n} \lambda_{j}^{4} x_{j}^{4 N D} \leq X^{4 N D} ; \\
\sum_{j=1}^{n} \lambda_{j}^{4} z_{j}^{34 D} \leq Z^{34 D} ; \sum_{j=1}^{n} \lambda_{j}^{4} z_{j}^{34 N D}=Z^{34 N D} ; \\
\sum_{j=1}^{n} \lambda_{j}^{4} y_{j} \geq Y ; \sum_{j=1}^{n} \lambda_{j}^{4}=1 ; \lambda^{4} \geq 0
\end{array}\right\} ;
\end{aligned}
$$

$$
T_{v}=\left\{\begin{array}{l|l}
\left(\begin{array}{l}
X^{k D} \\
X^{k N D}
\end{array}\right. & \sum_{j=1}^{n} \lambda_{j}^{k} x_{j}^{k D} \leq X^{k D} ; \sum_{j=1}^{n} \lambda_{j}^{k} x_{j}^{k N D} \leq X^{k N D} ; \\
Z^{k(k+1) D} & \sum_{j=1}^{n} \lambda_{j}^{k} z_{j}^{k(k+1) D} \geq Z^{k(k+1) D} ; \\
Z^{k(k+1) N D} & ; \sum_{j=1}^{n} \lambda_{j}^{k} z_{j}^{k(k+1) N D}=Z^{k(k+1) N D} ; \\
Y^{k} & \sum_{j=1}^{n} \lambda_{j}^{k} y_{j}^{k} \leq Y^{k} ; \\
X^{4 D} & \sum_{j=1}^{n} \lambda_{j}^{k+1} z_{j}^{k(k+1) D} \leq Z^{k(k+1) D} ; \\
Y & \sum_{j=1}^{n} \lambda_{j}^{k+1} z_{j}^{k(k+1) N D}=Z^{k(k+1) N D} ; \\
& \sum_{j=1}^{n} \lambda_{j}^{4} x_{j}^{4 D} \leq X^{4 D} ; \sum_{j}^{n} \lambda_{j}^{4} x_{j}^{4 N D} \leq X^{4 N D} ; \\
& \sum_{j=1}^{n} \lambda_{j}^{4} y_{j} \geq Y ; \sum_{j=1}^{n} \lambda_{j}^{k}=1 ; \sum_{j=1}^{n} \lambda_{j}^{4}=1 ; \\
& \lambda^{k} \geq 0 ; \lambda^{4} \geq 0 ; k=1,2,3
\end{array}\right\}
$$

To evaluate the performance of $D M U_{o}$, the following input-oriented radial network model is suggested that is written according to total PPS:

$\min \theta$;

$$
\begin{aligned}
& \sum_{j=1}^{n} \lambda_{j}^{1} x_{i j}^{1} \leq \theta x_{i o}^{1}, \quad i \in D^{1} ; \\
& \sum_{j=1}^{n} \lambda_{j}^{1} x_{i j}^{1} \leq x_{i o}^{1}, i \in N D^{1} ;
\end{aligned}
$$




$$
\begin{aligned}
& \sum_{j=1}^{n} \lambda_{j}^{1} z_{l j}^{12} \geq \sum_{j=1}^{n} \lambda_{j}^{2} z_{l j}^{12}, \quad l \in D^{12} ; \\
& \sum_{j=1}^{n} \lambda_{j}^{1} z_{l j}^{12}=z_{l o}^{12}, \quad l \in N D^{12} ; \\
& \sum_{j=1}^{n} \lambda_{j}^{2} z_{l j}^{12}=z_{l o}^{12}, l \in N D^{12} ; \\
& \sum_{j=1}^{n} \lambda_{j}^{1} y_{r j}^{1} \leq y_{r o}^{1}, r \in R^{1} ; \\
& \sum_{j=1}^{n} \lambda_{j}^{2} x_{i j}^{2} \leq \theta x_{i o}^{2}, i \in D^{2} ; \\
& \sum_{j=1}^{n} \lambda_{j}^{2} x_{i j}^{2} \leq x_{i o}^{2}, i \in N D^{2} \text {; } \\
& \sum_{j=1}^{n} \lambda_{j}^{2} z_{l j}^{23} \geq \sum_{j=1}^{n} \lambda_{j}^{3} z_{l j}^{23}, l \in D^{23} ; \\
& \sum_{j=1}^{n} \lambda_{j}^{2} z_{l j}^{23}=z_{l o}^{23}, \quad l \in N D^{23} ; \\
& \sum_{j=1}^{n} \lambda_{j}^{3} z_{l j}^{23}=z_{l o}^{23}, l \in N D^{23} ; \\
& \sum_{j=1} \lambda_{j}^{2} y_{r j}^{2} \leq y_{r o}^{2}, r \in R^{2} ; \\
& \sum_{j=1}^{n} \lambda_{j}^{3} x_{i j}^{3} \leq \theta x_{i o}^{3}, \quad i \in D^{3} ; \\
& \sum_{j=1}^{n} \lambda_{j}^{3} x_{i j}^{3} \leq x_{i o}^{3}, i \in N D^{3} ; \\
& \sum_{j=1}^{n} \lambda_{j}^{3} z_{l j}^{34} \geq \sum_{j}^{n} \lambda_{j}^{4} z_{l j}^{34}, l \in D^{34} ; \\
& \sum_{j=1}^{n} \lambda_{j}^{3} Z_{l j}^{34}=Z_{l o}^{34}, l \in N D^{34} ; \\
& \sum_{j=1}^{n} \lambda_{j}^{3} Z_{l j}^{34}=Z_{l o}^{34}, l \in N D^{34} ; \\
& \sum_{j=1}^{n} \lambda_{j}^{4} Z_{l j}^{34}=Z_{l o}^{34}, \quad l \in N D^{34} ; \\
& \sum_{j=1}^{n} \lambda_{j}^{3} y_{r j}^{3} \leq y_{r o}^{3}, r \in R^{3} ; \\
& \sum_{j=1}^{n} \lambda_{j}^{4} x_{i j}^{4} \leq \theta x_{i o}^{4}, i \in D^{4} ; \\
& \sum_{j=1}^{n} \lambda_{j}^{4} x_{i j}^{4} \leq x_{i o}^{4}, i \in N D^{4} ; \\
& \sum_{j=1}^{n} \lambda_{j}^{4} y_{r j} \geq y_{r o}, \quad r=1,2, \ldots, s \text {; } \\
& \sum_{j=1}^{n} \lambda_{j}^{1}=1 ; \sum_{j=1}^{n} \lambda_{j}^{2}=1 ; \sum_{j=1}^{n} \lambda_{j}^{3}=1 ; \sum_{j=1}^{n} \lambda_{j}^{4}=1 ; \\
& \lambda_{j}^{1}, \lambda_{j}^{2}, \lambda_{j}^{3}, \lambda_{j}^{4} \geq 0, j=1, \ldots, n, \theta: \text { free. }
\end{aligned}
$$

where:

1. For $f=1,2,3,4$, constraints

$$
\sum_{j=1}^{n} \lambda_{j}^{f} x_{i j}^{f} \leq \theta x_{i o}^{f}, i \in D^{f}
$$

are written corresponding to discretionary inputs and constraints

$$
\sum_{j=1}^{n} \lambda_{j}^{f} x_{i j}^{f} \leq x_{i o}^{f}, i \in N D^{f}
$$

are written corresponding to non-discretionary inputs of stage $S_{f}$.

2. For $k_{1}=1,2,3$, constraints

$$
\sum_{j=1}^{n} \lambda_{j}^{k_{1}} Z_{l j}^{k_{1}, k_{1}+1} \geq \sum_{j=1}^{n} \lambda_{j}^{k_{1}+1} Z_{l j}^{k_{1}, k_{1}+1}, l \in D^{k_{1}, k_{1}+1}
$$

are written corresponding to Discretionary outputs stage $S_{k_{1}}$ which shows that convex composition of these outputs as inputs of stage $S_{k_{1}+1}$ must be equal to or less than pro-duct of stage $S_{k_{1}}$.

3. For $k_{1}=1,2,3$, constraints

$$
\sum_{j=1}^{n} \lambda_{j}^{k_{1}} Z_{l j}^{k_{1}, k_{1}+1}=\sum_{j=1}^{n} \lambda_{j}^{k_{1}+1} Z_{l j}^{k_{1}, k_{1}+1}=Z_{l o}^{k_{1}, k_{1}+1}, l \in N D^{k_{1}, k_{1}+1}
$$

are written corresponding to non-discretionary outputs of stage $S_{k_{1}}$ and shows that the product of stage $S_{k_{1}}$ as non-discretionary output, must be equal to input of stage $S_{k_{1}+1}$ and non-discretionary output of $D M U_{o}$ in stage $S_{k_{1}}$.

4. For $\alpha=1,2,3$ and $r \in R^{\alpha}$, constraints

$$
\sum_{j=1}^{n} \lambda_{j}^{\alpha} y_{r j}^{\alpha} \leq y_{r o}^{\alpha}
$$

are written corresponding to undesirable outputs of stage $S_{\alpha}$ and shows that for $r \in R^{\alpha}$, convex composition of undesirable output of $D M U_{s}$ in stage $S_{\alpha}$ must be equal to or less than $r$-th output of $D M U_{o}$ in this stage $S_{k_{1}}$.

5. For $r=1,2, \ldots, s$, constraints

$$
\sum_{j=1}^{n} \lambda_{j}^{4} y_{r j} \geq y_{r o}
$$

are written corresponding to final outputs.

Theorem 2: Model (7) is always feasible.

Argument: Since the solution below is a feasible solution to the model (7), so this model will be feasible: 
$\theta=1$

$\lambda_{j}^{1}=\left(\lambda_{1}^{1}, \ldots, \lambda_{o}^{1}, \ldots, \lambda_{n}^{1}\right)=(0, \ldots, 0,1,0, \ldots, 0)$;

$\lambda_{j}^{2}=\left(\lambda_{1}^{2}, \ldots, \lambda_{o}^{2}, \ldots, \lambda_{n}^{2}\right)=(0, \ldots, 0,1,0, \ldots, 0)$;

$\lambda_{j}^{3}=\left(\lambda_{1}^{3}, \ldots, \lambda_{o}^{3}, \ldots, \lambda_{n}^{3}\right)=(0, \ldots, 0,1,0, \ldots, 0)$;

$\lambda_{j}^{4}=\left(\lambda_{1}^{4}, \ldots, \lambda_{o}^{4}, \ldots, \lambda_{n}^{4}\right)=(0, \ldots, 0,1,0, \ldots, 0)$;

Definition 3: The corresponding supply chain $D M U o$ is efficient in evaluating with model (7), if $\theta^{*}=1$.

In the following, measuring efficiency of the stages and the relationship between the efficiency of each stage with the overall efficiency are discussed. In order to evaluate the efficiency of each stage in the supply chain, we consider the dual form of model (7) as follows:

$$
\begin{gathered}
\max Z_{o}=-\sum_{i \in N D^{1}} \bar{v}_{i 1} x_{l o}^{1}+\sum_{l \in N D^{12}} \varphi_{l 2} Z_{l o}^{12}+\sum_{l \in N D^{12}} \varphi_{l 3} Z_{l o}^{12}- \\
-\sum_{r \in R^{1}} u_{r 1} y_{r o}^{1}-\sum_{i \in N D^{2}} \bar{v}_{i 2} x_{l o}^{2}+\sum_{l \in N D^{23}} \mu_{l 2} Z_{l o}^{23}+\sum_{l \in N D^{23}} \mu_{l 3} Z_{l o}^{23}- \\
-\sum_{r \in R^{2}} u_{r 2} y_{r o}^{2}-\sum_{i \in N D^{3}} \bar{v}_{i 3} x_{i o}^{3}+\sum_{l \in N D^{34}} p_{l 2} Z_{l o}^{34}+\sum_{l \in N D^{34}} p_{l 3} Z_{l o}^{34}- \\
-\sum_{r \in R^{3}} u_{r 3} y_{r o}^{3}-\sum_{i \in N D^{4}} \bar{v}_{i 4} x_{i o}^{4}+\sum_{r=1}^{s} w_{r} y_{r o}+ \\
+u_{1 o}+u_{2 o}+u_{3 o}+u_{4 o} ;
\end{gathered}
$$$$
-\sum_{i \in D^{1}} v_{i 1} x_{i j}^{1}-\sum_{i \in N D^{1}} \bar{v}_{i l} x_{i j}^{1}+\sum_{l \in D^{12}} \varphi_{l 1} Z_{l j}^{12}+\sum_{l \in N D^{12}} \varphi_{l 2} Z_{l j}^{12}-
$$$$
-\sum_{r \in R^{1}} u_{r 1} y_{r j}^{1}+u_{1 o} \leq 0, j=1,2, \ldots, n ;
$$$$
-\sum_{l \in D^{23}} \mu_{l 1} Z_{l j}^{23}+\sum_{l \in N D^{23}} \mu_{l 3} Z_{l j}^{23}-\sum_{i \in D^{3}} v_{i 3} x_{i j}^{3}-\sum_{i \in N D^{3}} \bar{v}_{i 3} x_{i j}^{3}+
$$$$
+\sum_{E \in D^{34}} p_{l 1} Z_{l j}^{34}+\sum_{l \in N D^{34}} p_{l 2} Z_{l j}^{34}-\sum_{r \in R^{3}} u_{r 3} y_{r j}^{3}+u_{3 o} \leq 0,
$$$$
j=1,2, \ldots, n \text {; }
$$$$
-\sum_{l \in D^{12}} \varphi_{l 1} Z_{l j}^{12}+\sum_{l \in N D^{12}} \varphi_{l 3} Z_{l j}^{12}-\sum_{i \in D^{2}} v_{i 2} x_{i j}^{2}-\sum_{i \in N D^{2}} \bar{v}_{i 2} x_{i j}^{2}+
$$$$
+\sum_{l \in D^{23}} \mu_{l 1} Z_{l j}^{23}+\sum_{l \in N D^{3}} \mu_{l 2} Z_{l j}^{23}-\sum_{r \in R^{2}} u_{r 2} y_{r j}^{2}+u_{2 o} \leq 0,
$$$$
j=1,2, \ldots, n \text {; }
$$

$$
\begin{gathered}
-\sum_{l \in D^{34}} p_{l 1} Z_{l j}^{34}+\sum_{l \in N D^{34}} p_{l 3} Z_{l j}^{34}-\sum_{i \in D^{4}} v_{i 4} x_{i j}^{4}-\sum_{i \in N D^{4}} \bar{v}_{i 4} x_{i j}^{4}+ \\
+\sum_{r=1}^{s} w_{r} y_{r j}+u_{4 o} \leq 0, j=1,2, \ldots, n \\
\sum_{i \in D^{1}} v_{i 1} x_{i o}^{1}+\sum_{i \in D^{2}} v_{i 2} x_{i o}^{2}+\sum_{i \in D^{3}} v_{i 3} x_{i o}^{3}+\sum_{i \in D^{4}} v_{i 4} x_{i o}^{4}=1 \\
v_{i f} \geq 0, i \in D^{f}, f=1,2,3,4 \\
\bar{v}_{i f} \geq 0, i \in N D^{f}, f=1,2,3,4 \\
\varphi_{l 1} \geq 0, \quad l \in D^{12} ; \\
\mu_{l 1} \geq 0, l \in D^{23} ; \\
p_{l 1} \geq 0, l \in D^{34} ; \\
u_{r h} \geq 0, r \in R^{h}, h=1,2,3 \\
w_{r} \geq 0, \quad r=1,2, \ldots, s \\
\varphi_{l 2}, \varphi_{l 3}: \text { free }, l \in N D^{12} \\
\mu_{l 2}, \mu_{l 3}: \text { free }, l \in N D^{23} \\
p_{l 2}, p_{l 3}: \text { free }, l \in N D^{34} \\
p_{l 2}, p_{l 3}: \text { free }, l \in N D^{34} \\
u_{t 0}: \text { free }, t=1,2,3,4
\end{gathered}
$$

Suppose that $Z_{o}^{*}$ is the value of objective function in model (9) for each optimal solution. In this case, overall efficiency of supply chain corresponding to $D M U_{o}$ is equal to:

$$
\begin{aligned}
Z_{o}^{*}= & -\sum_{i \in N D^{1}} \bar{v}_{i 1}^{*} x_{i o}^{1}+\sum_{l \in N D^{12}} \varphi_{l 2}^{*} Z_{l o}^{12}+\sum_{l \in N D^{12}} \varphi_{l 3}^{*} Z_{l o}^{12}- \\
- & \sum_{r \in R^{1}} u_{r 1}^{*} y_{r o}^{1}-\sum_{i \in N D^{2}} \bar{v}_{i 2}^{*} x_{i o}^{2}+\sum_{l \in N D^{23}} \mu_{l 2}^{*} Z_{l o}^{23}+ \\
& +\sum_{l \in N D^{23}} \mu_{l 3}^{*} Z_{l o}^{23}-\sum_{r \in R^{2}} u_{r 2}^{*} y_{r o}^{2}-\sum_{i \in N D^{3}} \bar{v}_{i 3}^{*} x_{i o}^{3}+ \\
+ & \sum_{l \in N D^{34}} p_{l 2}^{*} Z_{l o}^{34}+\sum_{l \in N D^{34}} p_{l 3}^{*} Z_{l o}^{34}-\sum_{l \in N D^{34}} p_{l 2}^{*} Z_{l o}^{34}+ \\
+ & \sum_{l \in N D^{34}} p_{l 3}^{*} Z_{l o}^{34}-\sum_{r \in R^{3}} u_{r 3}^{*} y_{r o}^{3}-\sum_{i \in N D^{4}} \bar{v}_{i 4}^{*} x_{i o}^{4}+ \\
& +\sum_{r=1}^{s} w_{r}^{*} y_{r o}+u_{1 o}^{*}+u_{2 o}^{*}+u_{3 o}^{*}+u_{4 o}^{*} .
\end{aligned}
$$

Definition 4: If $Z_{o}^{*}=1$ then $D M U_{o}$ or the chain corresponding to it, is efficient, otherwise it will be inefficient. 
It is concluded from the series of first, second, third and fourth constraints in model (9) and the last constraint that for the optimal solution and for $j=0$ :

$$
\begin{gathered}
-\sum_{i \in D^{1}} v_{i 1}^{*} x_{i o}^{1}-\sum_{i \in N D^{1}} \bar{v}_{i 1}^{*} x_{i o}^{1}+\sum_{l \in D^{12}} \varphi_{l 1}^{*} Z_{l o}^{12}+ \\
+\sum_{l \in N D^{12}} \varphi_{l 2}^{*} Z_{l o}^{12}-\sum_{r \in R^{1}} u_{r 1}^{*} y_{r o}^{1}+u_{1 o}^{*} \leq 0 \\
-\sum_{l \in D^{12}} \varphi_{l 1}^{*} Z_{l o}^{12}+\sum_{l \in N D^{12}} \varphi_{l 3}^{*} Z_{l o}^{12}-\sum_{i \in D^{2}} v_{i 2}^{*} x_{i o}^{2}-\sum_{i \in N D^{2}} \bar{v}_{i 2}^{*} x_{i o}^{2}+ \\
+\sum_{l \in D^{23}} \mu_{l 1}^{*} Z_{l o}^{23}+\sum_{l \in N D^{3}} \mu_{l 2}^{*} Z_{l o}^{23}-\sum_{r \in R^{2}} u_{r 2}^{*} y_{r o}^{2}+u_{2 o}^{*} \leq 0 \\
-\sum_{l \in D^{23}} \mu_{l 1}^{*} Z_{l o}^{23}+\sum_{l \in N D^{23}} \mu_{l 3}^{*} Z_{l o}^{23}-\sum_{i \in D^{3}} v_{i 3}^{*} x_{i o}^{3}-\sum_{i \in N D^{3}} \bar{v}_{i 3}^{*} x_{i o}^{3}+ \\
+\sum_{l \in D^{34}} p_{l 1}^{*} Z_{l o}^{34}+\sum_{l \in N D^{34}} p_{l 2}^{*} Z_{l o}^{34}-\sum_{r \in R^{3}} u_{r 3}^{*} y_{r o}^{3}+u_{3 o}^{*} \leq 0 \\
-\sum_{l \in D^{34}} p_{l 1}^{*} Z_{l o}^{34}+\sum_{l \in N D^{34}} p_{l 3}^{*} Z_{l o}^{34}-\sum_{i \in D^{4}} v_{i 4}^{*} x_{i o}^{4}- \\
-\sum_{i \in N D^{4}} \bar{v}_{i 4}^{*} x_{i o}^{4}+\sum_{r=1}^{s} w_{r}^{*} y_{r o}+u_{t o}^{*} \leq 0 \\
\sum_{i \in D^{1}} v_{i 1}^{*} x_{i o}^{1}+\sum_{i \in D^{2}} v_{i 2}^{*} x_{i o}^{2}+\sum_{i \in D^{3}} v_{i 3}^{*} x_{i o}^{3}+\sum_{i \in D^{4}} v_{i 4}^{*} x_{i o}^{4}=1
\end{gathered}
$$

From inequalities (11), (12), (13) and (14), it resulted that:

$$
\begin{aligned}
& \frac{\sum_{l \in D^{12}} \varphi_{l 1}^{*} Z_{l o}^{12}+\sum_{l \in N D^{12}} \varphi_{l 2}^{*} Z_{l o}^{12}+u_{1 o}^{*}}{\sum_{i \in D^{1}} v_{i 1}^{*} x_{i o}^{1}+\sum_{i \in N D^{1}} \bar{v}_{i 1}^{*} x_{i o}^{1}+\sum_{r \in R^{1}} u_{r 1}^{*} y_{r o}^{1}} \leq 1 \\
& \frac{\sum_{l \in N D^{12}} \varphi_{l 3}^{*} Z_{l o}^{12}+\sum_{l \in D^{23}} \mu_{l 1}^{*} Z_{l o}^{23}+\sum_{l \in N D^{3}} \mu_{l 2}^{*} Z_{l o}^{23}+u_{2 o}^{*}}{\sum_{l \in D^{12}} \varphi_{l 1}^{*} Z_{l o}^{12}+\sum_{i \in D^{2}} v_{i 2}^{*} x_{i o}^{2}+\sum_{i \in N D^{2}} \bar{v}_{i 2}^{*} x_{i o}^{2}+\sum_{r \in R^{2}} u_{r 2}^{*} y_{r o}^{2}} \leq 1 \\
& \frac{\sum_{l \in N D^{23}} \mu_{l 3}^{*} Z_{l o}^{23}+\sum_{l \in D^{34}} p_{l 1}^{*} Z_{l o}^{34}+\sum_{l \in N D^{34}} p_{l 2}^{*} Z_{l o}^{34}+u_{3 o}^{*}}{\sum_{l \in D^{23}} \mu_{l 1}^{*} Z_{l o}^{23}+\sum_{i \in D^{3}} v_{i 3}^{*} x_{i o}^{3}+\sum_{i \in N D^{3}} \bar{v}_{i 3}^{*} x_{i o}^{3}+\sum_{r \in R^{2}} u_{r 3}^{*} y_{r o}^{3}} \leq 1 \\
& \frac{\sum_{l \in N D^{34}} p_{l 3}^{*} Z_{l o}^{34}+\sum_{r=1}^{s} w_{r}^{*} y_{r o}+u_{4 o}^{*}}{\sum_{l \in D^{34}} p_{l 1}^{*} Z_{l o}^{34}+\sum_{i \in D^{4}} v_{i 4}^{*} x_{i o}^{4}+\sum_{i \in N D^{4}} \bar{v}_{i 4}^{*} x_{i o}^{4}} \leq 1 ;
\end{aligned}
$$

The deduction of the first side of the inequality (16), (17), (18) and (19), will respectively determine the efficiency of stages $S_{1}, S_{2}, S_{3}$ and $S_{4}$ of chain corresponding to $D M U_{0}$ which are represented by symbols $Z_{10}^{*}, Z_{20}^{*}, Z_{30}^{*}$ and $Z_{40}^{*}$.

Definition 5: If $Z_{t o}^{*}$, then the chain corresponding to $D M U_{o}$, is efficient in stage $S_{t}$.

Theorem 3: $D M U_{o}$ or the chain corresponding to it, is efficient if and only if $Z_{10}^{*}=1$, $Z_{2 o}^{*}=1, Z_{30}^{*}=1$ and $Z_{40}^{*}=1$.

\section{Argument:}

Suppose that $Z_{o}^{*}=1$.

Assume for proof by contradiction that $Z_{10}^{*}<1$, or $Z_{20}^{*}<1$, or $Z_{30}^{*}<1$, or $Z_{40}^{*}<1$.

Without loss of the generality of the argument, assume that $Z_{1 o}^{*}<1$, or $Z_{2 o}^{*} \leq 1$, or $Z_{3 o}^{*} \leq 1$, or $Z_{40}^{*} \leq 1$.

Hence, with respect to equations (16), (17), (18) and (19) we have:

$$
\begin{gathered}
-\sum_{i \in D^{1}} v_{l 1}^{*} x_{i o}^{1}-\sum_{i \in N D^{1}} \bar{v}_{i 1}^{*} x_{i o}^{1}+\sum_{l \in D^{12}} \varphi_{l 1}^{*} Z_{l o}^{12}+ \\
+\sum_{l \in N D^{12}} \varphi_{l 2}^{*} Z_{l o}^{12}-\sum_{r \in R^{1}} u_{r 1}^{*} y_{r o}^{1}+u_{1 o}^{*}<0 ; \\
-\sum_{l \in D^{12}} \varphi_{l 1}^{*} Z_{l o}^{12}+\sum_{l \in N D^{12}} \varphi_{l 3}^{*} Z_{l o}^{12}-\sum_{i \in D^{2}} v_{i 2}^{*} x_{i o}^{2}- \\
-\sum_{i \in N D^{2}} \bar{v}_{2}^{*} x_{i o}^{2}+\sum_{l \in D^{23}} \mu_{l 1}^{*} Z_{l o}^{23}+\sum_{l \in N D^{3}} \mu_{l 2}^{*} Z_{l o}^{23}- \\
-\sum_{r \in R^{2}} u_{r 2}^{*} y_{r o}^{2}+u_{2 o}^{*} \leq 0 ; \\
-\sum_{l \in D^{23}} \mu_{l 1}^{*} Z_{l o}^{23}+\sum_{l \in N D^{23}} \mu_{l 3}^{*} Z_{l o}^{23}-\sum_{i \in D^{3}} v_{i 3}^{*} x_{i o}^{3}- \\
-\sum_{i \in N D^{3}} \bar{v}_{i 3}^{*} x_{i o}^{3}+\sum_{l \in D^{34}} p_{l 1}^{*} Z_{l o}^{34}+\sum_{l \in N D^{34}} p_{l 2}^{*} Z_{l o}^{34}- \\
-\sum_{r \in R^{3}} u_{r 3}^{*} y_{r o}^{3}+u_{3 o}^{*} \leq 0 \\
-\sum_{l \in D^{34}} p_{l 1}^{*} Z_{l o}^{34}+\sum_{l \in D^{34}} p_{l 3}^{*} Z_{l o}^{34}-\sum_{i \in D^{4}} v_{i 4}^{*} x_{i o}^{4}- \\
-\sum_{i \in N D^{4}} \bar{v}_{i 4}^{*} x_{i o}^{4}+\sum_{r=1}^{s} w_{r}^{*} y_{r o}+u_{4 o}^{*} \leq 0 .
\end{gathered}
$$

Now by summing the sides of the four inequalities and the equation 


$$
\sum_{i \in D^{1}} v_{i 1}^{*} x_{i o}^{1}+\sum_{i \in D^{2}} v_{i 2}^{*} x_{i o}^{2}+\sum_{i \in D^{3}} v_{i 3}^{*} x_{i o}^{3}+\sum_{i \in D^{4}} v_{i 4}^{*} x_{i o}^{4}=1
$$

we have:

$$
\begin{gathered}
-\sum_{i \in D^{1}} \bar{v}_{i 1}^{*} x_{i o}^{1}+\sum_{l \in N D^{12}} \varphi_{l 2}^{*} Z_{l o}^{12}+\sum_{l \in N D^{12}} \varphi_{l 3}^{*} Z_{l o}^{12}-\sum_{r \in R^{1}} u_{r 1}^{*} y_{r o}^{1}- \\
-\sum_{i \in N D^{2}} \bar{v}_{i 2}^{*} x_{i o}^{2}+\sum_{l \in N D^{23}} \mu_{l 2}^{*} Z_{l o}^{23}+\sum_{l \in N D^{23}} \mu_{l 3}^{*} Z_{l o}^{23}- \\
-\sum_{r \in R^{2}} u_{r 2}^{*} y_{r o}^{2}-\sum_{i \in N D^{3}} \bar{v}_{i 3}^{*} x_{i o}^{3}+\sum_{l \in N D^{34}} p_{l 2}^{*} Z_{l o}^{34} .
\end{gathered}
$$

So we have $Z_{o}^{*}<1$ which is against the original assumption, therefore $Z_{10}^{*}=Z_{20}^{*}=Z_{30}^{*}=Z_{40}^{*}=1$.

Now inversely suppose that $Z_{1 l}^{*}=Z_{2 l}^{*}=Z_{3 l}^{*}=$ $=Z_{4 l}^{*}=1$.

From equations (16), (17), (18) and (19) we have:

$$
\begin{aligned}
& -\sum_{i \in D^{1}} v_{i 1}^{*} x_{i o}^{1}-\sum_{i \in N D^{1}} \bar{v}_{i 1}^{*} x_{i o}^{1}+\sum_{l \in D^{12}} \varphi_{l 1}^{*} Z_{l o}^{12}+ \\
& +\sum_{l \in N D^{12}} \varphi_{l 2}^{*} Z_{l o}^{12}-\sum_{r \in R^{1}} u_{r 1}^{*} y_{r o}^{1}+u_{1 o}^{*}=0 ; \\
& -\sum_{l \in D^{12}} \varphi_{l 1}^{*} Z_{l o}^{12}+\sum_{l \in N D^{12}} \phi_{l 3}^{*} Z_{l o}^{12}-\sum_{i \in D^{2}} v_{i 2}^{*} x_{i o}^{2}- \\
& -\sum_{i \in N D^{2}} \bar{v}_{i 2}^{*} x_{i o}^{2}+\sum_{l \in D^{23}} \mu_{l 1}^{*} Z_{l o}^{23}+\sum_{l \in N D^{3}} \mu_{l 2}^{*} Z_{l o}^{23}- \\
& -\sum_{r \in R^{2}} u_{r 2}^{*} y_{r o}^{2}+u_{2 o}^{*}=0 ; \\
& -\sum_{l \in D^{23}} \mu_{l 1}^{*} Z_{l o}^{23}+\sum_{l \in N D^{23}} \mu_{l 3}^{*} Z_{l o}^{23}-\sum_{i \in D^{3}} v_{i 3}^{*} x_{i o}^{3}- \\
& -\sum_{i \in N D^{3}} \bar{v}_{i 3}^{*} x_{i o}^{3}+\sum_{l \in D^{34}} p_{l 1}^{*} Z_{l o}^{34}+\sum_{l \in N D^{34}} p_{l 2}^{*} Z_{l o}^{34}- \\
& -\sum_{r \in R^{3}} u_{r 3}^{*} y_{r o}^{3}+u_{3 o}^{*}=0 ; \\
& -\sum_{l \in D^{12}} \varphi_{l 1}^{*} Z_{l o}^{12}+\sum_{l \in N D^{12}} \varphi_{l 3}^{*} Z_{l o}^{12}-\sum_{i \in D^{2}} v_{i 2}^{*} x_{i o}^{2}- \\
& -\sum_{i \in N D^{2}} \bar{v}_{i 2}^{*} x_{i o}^{2}+\sum_{l \in D^{23}} \mu_{l 1}^{*} Z_{l o}^{23}+\sum_{l \in N D^{3}} \mu_{l 2}^{*} Z_{l o}^{23}- \\
& -\sum_{r \in R^{2}} u_{r 2}^{*} y_{r o}^{2}+u_{2 o}^{*}=0 ;
\end{aligned}
$$
and

$$
\sum_{i \in D^{1}} v_{i 1}^{*} x_{i o}^{1}+\sum_{i \in D^{2}} v_{i 2}^{*} x_{i o}^{2}+\sum_{i \in D^{3}} v_{i 3}^{*} x_{i o}^{3}+\sum_{i \in D^{4}} v_{i 4}^{*} x_{i o}^{4}=1,
$$

we conclude that $Z_{o}^{*}=1$, so $D M U_{o}$ or the corresponding chain, is efficient.
In order to provide an expert opinion for some of the indicators preference over each other and the influence of this approach on the efficiency of the supply chain, we attempted to determine the weights for the indicators using the fuzzy decision-making technique and expert opinion survey. We add the considered weight constraints (equations 29) to the model (9) to help more accurately estimate the supply chain efficiency:

$$
\begin{aligned}
& u_{11} \geq(0.165 / 0.132) \cdot \varphi_{31} ; \\
& \varphi_{31} \geq(0.132 / 0.116) \cdot \varphi_{51} ; \\
& \varphi_{51} \geq(0.116 / 0.103) \cdot \bar{v}_{12} ; \\
& p_{21} \geq(0.147 / 0.146) \cdot p_{11} ; \\
& p_{11} \geq(0.146 / 0.140) \cdot p_{41} ; \\
& p_{41} \geq(0.140 / 0.122) \cdot v_{24} ; \\
& \bar{v}_{11} \geq(0.185 / 0.132) \cdot v_{51} ;
\end{aligned}
$$

\section{Case study}

Green supply chain management is one of the critical issues in organizations that managers need to design appropriate models for performance evaluation. In this regard, in some cases, we may encounter undesirable outputs such as environmental pollutants. In addition to special indicators, undesirable and environmental factors must be considered for correct evaluation of Cement companies in the framework of the supply chain.

The evaluation of cement factories in the country in the form of complete supply chains and attention to these undesirable and negative factors, as well as Non-Discretionary factors that are partly or fully out of management control, was one incentive to perform this research. For this purpose, according to the opinion of experts and based on theoretical studies conducted in previous research and methods for selecting the indicators, suitable indicators for the Iranian cement industry were determined in accordance with the following tables (Tables 1-4). Also, among these performance indicators, special indicators such as non-discretionary inputs and outputs, undesirable outputs and negative outputs have been specified. 
To illustrate the application of the proposed method, we consider the actual data of the 42 cement companies listed on the Tehran stock exchange during one year with the inputs, outputs, and intermediate data in accordance with the above tables. We ran the model (9) by defining weight constraints for some of the indicators based on the expert opinion and by considering theorem 1 for the negative outputs of the fourth stage. By applying this model, the efficiency of each company was determined as well as the efficiency of each stage of their corresponding chains based on the explanations given in the previous sections. The results are shown in Table 5.

We calculate the efficiency correlation coefficient of each company with its distance to the center of the soil mine (silica) and its distance to the center of the province. Tables 7 and 8 show this correlation coefficient.

Also, the variance of the total efficiency and the efficiency of each stage are calculated for companies and are presented in Table 9.

The efficiency correlation coefficient of the supplier stage with the distance from the company to the soil mine is equal to 0.261 , which is greater than the correlation coefficient of the efficiency of other stages and the total efficiency with the distance to the mine. This shows that this stage has the highest relationship with the distance between companies and the mine compared to other stages. The low correlation coefficient of customer stage efficiency $(-0.011)$ with the distance to the mine shows that there is no significant relationship between this stage and the distance of companies to the mine.

The high correlation coefficient of the efficiency of the distributor stage with the distance of companies to the center of the province $(0.385)$ indicates that for the distribution of the product, the distance from the factory to the center of the province is very important and there is a significant relationship between the distributor stage and this distance. There is no significant relationship between the supplier stage and the dis- tance between the factories and the center of the province because the correlation coefficient of this stage is the lowest value, 0.063 .

The variance of the manufacturer stage is 0.0005. The difference between the maximum and minimum values of the efficiencies at this stage is a small number of $0.07(1-0.93=0.07)$. Therefore, all companies in cement production have similar performance and there is no significant difference between their efficiency at this stage.

The efficiency variance of cement companies in the customer stage $(0.0733)$ is greater than the efficiency variance of other stages and the total efficiency variance. This indicates that the efficiency dispersion of the units is high at this stage. The value of variance for the supplier and distributor stages shows that the performance of the chains in these two stages is close to each other and the value of variance of total efficiency (0.0153) indicates that the dispersion of total efficiency of 42 supply chains is relatively high.

\section{Conclusion}

In this study, the status of the green supply chain including four stages of supplier, manufacturer, distributor and customer is investigated. In addition, the authors have attempted to evaluate the efficiency of this chain with inputs and outputs that have a specific structure, including non-discretionary inputs and outputs, undesirable outputs, and negative outputs which are investigated. The results show that among 42 green supply chains with this structure, there are six efficient and 36 inefficient chains. In addition, chains that have been fully efficient and have achieved an efficiency score of 1 are efficient in all four stages. Inefficient chains are inefficient at least in one stage, which also confirms the stated proposition. The most inefficient supply chain relates to the Sepahan factory (Unit 11) whose efficiency score is $\theta^{*}=0.5352$. As can be seen, this unit is only efficient in the supplier stage and it is inefficient in the other three stages, as it has very poor performance in the fourth stage. The efficiency score of all companies in the manufacturer stage 
Introducing indicators and their definition for $j$-th decision-making unit in inputs and intermediate data

Table 1.

\begin{tabular}{|c|c|c|c|c|}
\hline \multicolumn{2}{|c|}{ Symbols } & $\begin{array}{l}\text { Discretionary or } \\
\text { non-discretionary }\end{array}$ & $\begin{array}{l}\text { Indicator } \\
\text { classification }\end{array}$ & Indicator title \\
\hline \multirow{6}{*}{$X_{i j}^{1}$} & $X_{1 j}^{1}$ & \multirow{5}{*}{$D$} & \multirow{6}{*}{$\begin{array}{l}\text { Original input } \\
\text { of chain }\end{array}$} & Total current or operational costs \\
\hline & $X_{2 j}^{1}$ & & & $\begin{array}{l}\text { Total initial investment in mine exploitation } \\
\text { and plant process }\end{array}$ \\
\hline & $X_{3 j}^{1}$ & & & Total debt of the factory \\
\hline & $X_{4 j}^{1}$ & & & Total financial expenses \\
\hline & $X_{5 j}^{1}$ & & & Total amount of salary \\
\hline & $X_{6 j}^{1}$ & $N D$ & & $\begin{array}{l}\text { Quality of suppliers in terms of sustainability } \\
\text { in the supply of minerals and consumables }\end{array}$ \\
\hline \multirow{6}{*}{$Z_{l j}^{12}$} & $Z_{1 j}^{12}$ & \multirow{5}{*}{$D$} & \multirow{6}{*}{$\begin{array}{l}\text { Intermediate data } \\
\text { (output of stage } 1 \\
\text { and input } \\
\text { of stage 2) }\end{array}$} & Total mineral resources available \\
\hline & $Z_{2 j}^{12}$ & & & $\begin{array}{l}\text { Total tonnage of raw materials harvested from mines, } \\
\text { which should be consumed in the production process }\end{array}$ \\
\hline & $Z_{3 j}^{12}$ & & & $\begin{array}{c}\text { The tonnage of other chemical and mineral substances } \\
\text { consumed in the process of production }\end{array}$ \\
\hline & $Z_{4 j}^{12}$ & & & Total mineral raw materials stored for use in cold season \\
\hline & $Z_{5 j}^{12}$ & & & Total R\&D expenses \\
\hline & $Z_{6 j}^{12}$ & $N D$ & & Real industry capacity \\
\hline \multirow{2}{*}{$Z_{l j}^{23}$} & $Z_{1 j}^{23}$ & \multirow{2}{*}{$D$} & \multirow{2}{*}{$\begin{array}{l}\text { Intermediate data } \\
\text { (output of stage } 2 \\
\text { and input of stage } 3 \text { ) }\end{array}$} & Total clinker production capacity \\
\hline & $Z_{2 j}^{23}$ & & & Total cement production capacity \\
\hline \multirow{4}{*}{$Z_{l j}^{34}$} & $Z_{1 j}^{34}$ & \multirow{4}{*}{$N D$} & \multirow{4}{*}{$\begin{array}{l}\text { Intermediate data } \\
\text { (output of stage } 3 \\
\text { and input } \\
\text { of stage 4) }\end{array}$} & Total value of assets and inventories ready for sale \\
\hline & $Z_{2 j}^{34}$ & & & $\begin{array}{l}\text { Total tonnage of packaged and bulk cement sales } \\
\text { in the domestic market and exports }\end{array}$ \\
\hline & $Z_{3 j}^{34}$ & & & Total clinker sales tonnage \\
\hline & $Z_{4 j}^{34}$ & & & The cost of the product \\
\hline
\end{tabular}

is between 1 and 0.93 . Therefore, at this stage, all companies have similar performance and there is no significant difference between their efficiencies.

The efficiency correlation coefficient of the supplier stage with the distance to the center of the mine shows that the highest relationship is between the supplier and the distance to the mine, which means that the performance of suppliers will be higher due to closer proximity to the mine. Since most suppliers were at a short distance from the mine, the efficiency of all cement companies was high at the supplier stage. The efficiency correlation coefficient of 
Introducing indicators and their definition

Table 2.

for $j$-th decision-making unit in final output

\begin{tabular}{|c|c|c|c|c|}
\hline \multicolumn{2}{|c|}{ Symbols } & Status of indicator & Indicator classification & Indicator title \\
\hline \multirow{6}{*}{$Y_{r j}$} & $y_{1 j}$ & \multirow{3}{*}{ Non-negative } & \multirow{6}{*}{ Final output } & Total current assets \\
\hline & $y_{2 j}$ & & & Brand competitiveness and globalization \\
\hline & $y_{3 j}$ & & & Customer satisfaction \\
\hline & $y_{4 j}$ & \multirow{3}{*}{$\begin{array}{c}\text { Negative } \\
\text { or non-negative }\end{array}$} & & Total profit \\
\hline & $y_{5 j}$ & & & Annual growth rate based on performance \\
\hline & $y_{6 j}$ & & & Equity return \\
\hline
\end{tabular}

Introducing indicators and their definition

Table 3. for $j$-th decision-making unit in independent inputs of each stage

\begin{tabular}{c|c|c|c|c}
\hline \multicolumn{2}{c|}{ Symbols } & $\begin{array}{c}\text { Discretionary or } \\
\text { non-discretionary } \\
\text { indicators }\end{array}$ & $\begin{array}{c}\text { Indicator } \\
\text { classification }\end{array}$ & Indicator title \\
\hline$X_{i j}^{2}$ & $X_{1 j}^{2}$ & $N D$ & Independent inputs of Stage 2 & Total cost of energy payment \\
\hline$X_{i j}^{3}$ & $X_{1 j}^{3}$ & $D$ & Independent inputs of Stage 3 & Total cost for increasing reliability in the supply chain \\
\hline \multirow{2}{*}{$X_{i j}^{4}$} & $X_{1 j}^{4}$ & $D$ & Independent inputs of Stage 4 & Cost of environmentally friendly design \\
\cline { 2 - 2 } & $X_{2 j}^{4}$ & $D$ & & Total marketing fee \\
\hline
\end{tabular}

Introducing indicators and their definition

Table 4. for $j$-th decision-making unit in undesirable outputs

\begin{tabular}{|c|c|c|c|c|}
\hline \multicolumn{2}{|c|}{ Symbols } & $\begin{array}{l}\text { Status of } \\
\text { indicators }\end{array}$ & Indicator classification & Indicator title \\
\hline$Y_{i j}^{1}$ & $y_{1 j}^{1}$ & $U . D$ & Undesirable outputs of Stage1 & $\begin{array}{l}\text { Causing destructive environmental effects in } \\
\text { harvesting of mines }\end{array}$ \\
\hline \multirow{6}{*}{$Y_{i j}^{2}$} & $y_{1 j}^{2}$ & \multirow{6}{*}{$U . D$} & \multirow{6}{*}{$\begin{array}{l}\text { Undesirable outputs } \\
\text { of Stage2 }\end{array}$} & Total produced dust particles $\left(\mathrm{mg} / \mathrm{m}^{3}\right.$ ) \\
\hline & $y_{2 j}^{2}$ & & & Average annual emissions of NOx \\
\hline & $y_{3 j}^{2}$ & & & Average annual emissions of $\mathrm{CO}_{2}$ \\
\hline & $y_{4 j}^{2}$ & & & Average annual emissions of $\mathrm{SO}_{2}$ \\
\hline & $y_{5 j}^{2}$ & & & $\begin{array}{c}\text { Effect of total water and sewage intake in } \\
\text { groundwater }\end{array}$ \\
\hline & $y_{6 j}^{2}$ & & & $\begin{array}{l}\text { Impact of factory performance on the creation } \\
\text { of negative conditions in the ecosystem }\end{array}$ \\
\hline
\end{tabular}


Efficiency of all companies and efficiency

Table 5. of each chain stages corresponding to them

\begin{tabular}{|c|c|c|c|c|c|c|}
\hline Number & Company & $\begin{array}{c}\text { Total } \\
\text { efficiency }\end{array}$ & $\begin{array}{c}\text { Supplier stage } \\
\text { efficiency }\end{array}$ & $\begin{array}{l}\text { Manufacturer } \\
\text { stage efficiency }\end{array}$ & $\begin{array}{l}\text { Distributor stage } \\
\text { efficiency }\end{array}$ & $\begin{array}{l}\text { Customer stage } \\
\text { efficiency }\end{array}$ \\
\hline 1 & Abadeh & 0.8679 & 1.00 & 0.98 & 0.95 & 0.55 \\
\hline 2 & Abbey & 0.8955 & 1.00 & 1.00 & 0.85 & 1.00 \\
\hline 3 & Darab & 0.7090 & 0.80 & 0.96 & 0.89 & 0.57 \\
\hline 4 & Ardebil & 0.8308 & 1.00 & 0.93 & 0.87 & 0.68 \\
\hline 5 & Oroumiyeh & 0.6781 & 1.00 & 0.95 & 0.83 & 0.46 \\
\hline 6 & Saveh & 0.7078 & 1.00 & 1.00 & 0.95 & 0.29 \\
\hline 7 & Bagheran & 0.6810 & 0.77 & 0.97 & 0.80 & 0.50 \\
\hline 8 & Bojnourd & 0.8716 & 0.91 & 0.97 & 0.87 & 1.00 \\
\hline 9 & Sabzevar Lar & 0.9452 & 1.00 & 1.00 & 0.97 & 1.00 \\
\hline 10 & Behbahan & 0.9494 & 1.00 & 0.93 & 1.00 & 1.00 \\
\hline 11 & Sepahan & 0.5352 & 1.00 & 0.93 & 0.87 & 0.38 \\
\hline 12 & Tehran & 1 & 1.00 & 1.00 & 1.00 & 1.00 \\
\hline 13 & West Asia Complex & 0.6978 & 1.00 & 1.00 & 0.76 & 0.33 \\
\hline 14 & Khash & 0.8124 & 0.95 & 0.95 & 0.91 & 0.75 \\
\hline 15 & Khorramabad & 0.6981 & 0.89 & 0.97 & 0.88 & 0.27 \\
\hline 16 & Khazar & 0.8304 & 0.94 & 1.00 & 0.84 & 0.60 \\
\hline 17 & Majd Khaf & 1 & 1.00 & 1.00 & 1.00 & 1.00 \\
\hline 18 & Khoozestan & 1 & 1.00 & 1.00 & 1.00 & 1.00 \\
\hline 19 & Dashtestan Ce & 0.9697 & 1.00 & 1.00 & 0.99 & 1.00 \\
\hline 20 & Doroud & 0.7840 & 1.00 & 1.00 & 0.80 & 0.36 \\
\hline 21 & Shahroud & 0.7381 & 0.85 & 1.00 & 0.84 & 0.54 \\
\hline 22 & Shargh & 0.8456 & 1.00 & 1.00 & 0.89 & 0.67 \\
\hline 23 & Shomal & 0.8522 & 0.92 & 0.96 & 0.88 & 1.00 \\
\hline 24 & Isfahan & 0.6949 & 0.84 & 0.95 & 0.89 & 0.53 \\
\hline 25 & Soufian & 0.7976 & 0.92 & 0.99 & 0.82 & 0.76 \\
\hline 26 & Gharb & 0.7947 & 0.91 & 0.98 & 0.85 & 0.69 \\
\hline 27 & Fars Cement & 0.8577 & 1.00 & 0.98 & 0.88 & 0.64 \\
\hline 28 & Faraz Firozkouh & 0.8291 & 0.93 & 0.97 & 0.88 & 0.70 \\
\hline 29 & Urmia White & 0.9405 & 1.00 & 0.96 & 0.97 & 0.86 \\
\hline 30 & Siman Fars Noe & 0.8854 & 0.92 & 0.98 & 0.94 & 1.00 \\
\hline 31 & Firozkouh & 0.8395 & 1.00 & 0.97 & 0.87 & 0.79 \\
\hline 32 & Qayen & 1 & 1.00 & 1.00 & 1.00 & 1.00 \\
\hline 33 & Karoon & 0.9064 & 1.00 & 1.00 & 0.88 & 0.72 \\
\hline
\end{tabular}




\begin{tabular}{c|c|c|c|c|c|c}
\hline Number & Company & $\begin{array}{c}\text { Total } \\
\text { efficiency }\end{array}$ & $\begin{array}{c}\text { Supplier stage } \\
\text { efficiency }\end{array}$ & $\begin{array}{c}\text { Manufacturer } \\
\text { stage efficiency }\end{array}$ & $\begin{array}{c}\text { Distributor stage } \\
\text { efficiency }\end{array}$ & $\begin{array}{c}\text { Customer stage } \\
\text { efficiency }\end{array}$ \\
\hline 34 & Kordestan Ce. Co & 0.5810 & 0.81 & 0.98 & 0.84 & 0.15 \\
\hline 35 & Kerman & 0.9603 & 1.00 & 0.98 & 0.95 & 1.00 \\
\hline 36 & Larestan & 1 & 1.00 & 1.00 & 1.00 & 1.00 \\
\hline 37 & Mazandaran & 0.9383 & 1.00 & 1.00 & 0.85 & 1.00 \\
\hline 38 & Momtazan kerman & 0.9011 & 0.89 & 0.94 & 0.94 & 1.00 \\
\hline 39 & Neiriz & 1 & 1.00 & 1.00 & 1.00 & 1.00 \\
\hline 40 & Hormozgan & 0.9314 & 1.00 & 1.00 & 0.89 & 1.00 \\
\hline 41 & Hegmatan & 0.7213 & 0.93 & 0.98 & 0.83 & 0.45 \\
\hline 42 & Ilam & 0.6458 & 0.85 & 0.97 & 0.80 & 0.27 \\
\hline
\end{tabular}

\section{Distance of factory to center of province and soil mine (silica)}

\begin{tabular}{|c|c|c|c|c|c|c|c|}
\hline $\begin{array}{c}\text { Num- } \\
\text { ber }\end{array}$ & Company & $\begin{array}{l}\text { Distance } \\
\text { to soil mine } \\
\text { (silica) } \\
(\mathrm{Km})\end{array}$ & $\begin{array}{c}\text { Distance } \\
\text { to center of } \\
\text { province }(\mathrm{Km})\end{array}$ & $\begin{array}{c}\text { Num- } \\
\text { ber }\end{array}$ & Company & $\begin{array}{l}\text { Distance } \\
\text { to soil mine } \\
\text { (silica) } \\
(\mathrm{Km})\end{array}$ & $\begin{array}{c}\text { Distance } \\
\text { to center of } \\
\text { province }(\mathrm{Km})\end{array}$ \\
\hline 1 & Abadeh Cement & 10 & 228 & 22 & Shargh Cement & 6 & 259 \\
\hline 2 & Abik Cement & 4 & 68 & 23 & Shomal Cement & 5 & 119 \\
\hline 3 & Darab Cement & 5 & 350 & 24 & Esfahan Cement & 10 & 135 \\
\hline 4 & Ardebil Cement & 14 & 169 & 25 & Soufian Cement & 9 & 150 \\
\hline 5 & Urumia Cement & 10 & 201 & 26 & Gharb Cement & 8 & 126 \\
\hline 6 & Saveh Cement & 9 & 145 & 27 & Fars Cement & 10 & 155 \\
\hline 7 & Bagheran Cement & 8 & 494 & 28 & Faraz Firouzkouh Cement & 5 & 120 \\
\hline 8 & Bojnourd Cement & 6 & 208 & 29 & Urumia Cement & 6 & 178 \\
\hline 9 & Lar Sabzavar Cement & 8 & 355 & 30 & Farsno Cement & 4 & 202 \\
\hline 10 & Behbahan Cement & 9 & 239 & 31 & Firouzkouh Cement & 5 & 120 \\
\hline 11 & Sepahan Cement & 10 & 132 & 32 & Qaen Cement & 9 & 356 \\
\hline 12 & Tehran Cement & 15 & 81 & 33 & Karoun Cement & 7 & 296 \\
\hline 13 & West Asia Cement Complex & 10 & 316 & 34 & Kordestan Cement & 6 & 152 \\
\hline 14 & Khash Cement & 8 & 515 & 35 & Kerman Cement & 8 & 281 \\
\hline 15 & Khoramabad Cement & 6 & 203 & 36 & Larestan Cement & 9 & 406 \\
\hline 16 & Khazar Cement & 10 & 121 & 37 & Mazandaran Cement & 5 & 153 \\
\hline 17 & Majd Khaf Cement & 7 & 264 & 38 & Momtazan Kerman Cement & 8 & 283 \\
\hline 18 & Khouzestan Cement & 15 & 272 & 39 & Sefid Neyriz Cement & 6 & 341 \\
\hline 19 & Dashdestan Cement & 16 & 178 & 40 & Hormozgan Cement & 9 & 416 \\
\hline 20 & Doroud Cement & 8 & 171 & 41 & Hegmatan Cement & 10 & 178 \\
\hline 21 & Shahroud Cement & 7 & 254 & 42 & Ilam Cement & 9 & 132 \\
\hline
\end{tabular}


Table 7.

Efficiency correlation coefficient with its distance to the center of the soil mine (silica)

\begin{tabular}{c|c|c|c|c|c}
\hline Efficiency & Total & Supplier stage & Manufacturer stage & Distributor stage & Customer stage \\
\hline Correlation coefficient & 0.099 & 0.261 & 0.023 & 0.212 & -0.011 \\
\hline
\end{tabular}

Efficiency correlation coefficient with its distance to the center of the province

Table 8.

\begin{tabular}{c|c|c|c|c|c}
\hline Efficiency & Total & Supplier stage & Manufacturer stage & Distributor stage & Customer stage \\
\hline Correlation coefficient & 0.197 & 0.063 & 0.236 & 0.385 & 0.096 \\
\hline
\end{tabular}

\section{Efficiency variance}

Table 9.

\begin{tabular}{c|c|c|c|c|c}
\hline Efficiency & Total & Supplier stage & Manufacturer stage & Distributor stage & Customer stage \\
\hline Variance & 0.0153 & 0.0045 & 0.0005 & 0.0046 & 0.0733 \\
\hline
\end{tabular}

the distributor stage with the distance of the company to the center of the province where it is located indicates that the highest relationship is between the distributor and the distance to the center of the province. Therefore, the distance of companies to the geographical location of cement sales will have a significant impact on the performance of the distributor stage.
The authors focus in this study was to provide a radial model to evaluate the performance of green supply chain with inputs and outputs having a specific structure. Therefore, the authors suggest research to investigate the following: (1) provide non-radial models with this structure and (2) provide a model to determine the cause of supply chain inefficiency and provide solutions to improve their efficiency.

\section{References}

1. Färe R., Grosskopf S. (1997) Intertemporal production frontiers: with dynamic DEA. Journal of the Operational Research Society, vol. 48, no 6, pp. 656-656. DOI: 10.1057/palgrave.jors.2600779.

2. Färe R., Grosskopf S. (2000) Network DEA. Socio-Economic Planning Sciences, vol. 34, no 1, pp. 35-49. DOI: $10.1016 /$ S0038-0121(99)00012-9.

3. Tone K., Tsutsui M. (2009) Network DEA: A slacks-based measure approach. European Journal of Operational Research, vol. 197, no 1, pp. 243-252. DOI: 10.1016/j.ejor.2008.05.027.

4. Xu J., Li B., Wu D. (2009) Rough data envelopment analysis and its application to supply chain performance evaluation. International Journal of Production Economics, vol. 122, no 2, pp. 628-638. DOI: 10.1016/j.jpe.2009.06.026.

5. Saranga H., Moser R. (2010) Performance evaluation of purchasing and supply management using value chain DEA approach. European Journal of Operational Research, vol. 207, no 1, pp. 197-205. DOI: $10.1016 /$ j.ejor.2010.04.023.

6. Chen C., Yan H. (2011) Network DEA model for supply chain performance evaluation. European Journal of Operational Research, vol. 213, no 1, pp. 147-155. DOI: 10.1016/j.ejor.2011.03.010.

7. Azadeh A., Alem S.M. (2010) A flexible deterministic, stochastic and fuzzy Data Envelopment Analysis approach for supply chain risk and vendor selection problem: Simulation analysis. Expert Systems with Applications, vol. 37, no 12, pp. 7438-7448. DOI: 10.1016/j.eswa.2010.04.022. 
8. Babazadeh R., Razmi J., Rabbani M., Pishvaee M.S. (2017) An integrated data envelopment analysismathematical programming approach to strategic biodiesel supply chain network design problem. Journal of Cleaner Production, no 147, pp. 694-707. DOI: 10.1016/j.jclepro.2015.09.038.

9. Badiezadeh T., Saen R.F., Samavati T. (2018) Assessing sustainability of supply chains by double frontier network DEA: A big data approach. Computers \& Operations Research, no 98, pp. 284-290. DOI: 10.1016/j.cor.2017.06.003.

10. Boudaghi E., Saen R.F. (2018) Developing a novel model of data envelopment analysis-discriminant analysis for predicting group membership of suppliers in sustainable supply chain. Computers \& Operations Research, no 89, pp. 348-359. DOI: 10.1016/j.cor.2017.01.006.

11. Fathi A., Saen R.F. (2018) A novel bidirectional network data envelopment analysis model for evaluating sustainability of distributive supply chains of transport companies. Journal of Cleaner Production, no 184, pp. 696-708. DOI: 10.1016/j.jclepro.2018.02.256.

12. Goodarzi M., Saen R.F. (2020) How to measure bullwhip effect by network data envelopment analysis? Computers \& Industrial Engineering, no 139, article no 105431. DOI: 10.1016/j.cie.2018.09.046.

13. Grigoroudis E., Petridis K., Arabatzis G. (2014) RDEA: A recursive DEA based algorithm for the optimal design of biomass supply chain networks. Renewable Energy, no 71, pp. 113-122. DOI: 10.1016/j.renene.2014.05.001

14. Huang C.-W. (2018) Assessing the performance of tourism supply chains by using the hybrid network data envelopment analysis model, Tourism Management, no 65, pp. 303-316. DOI: 10.1016/j.tourman.2017.10.013.

15. Izadikhah M., Saen, R.F. (2016) Evaluating sustainability of supply chains by two-stage range directional measure in the presence of negative data. Transportation Research. Part D: Transport and Environment, no 49, pp. 110-126. DOI: 10.1016/j.trd.2016.09.003.

16. Izadikhah M., Saen, R.F., Ahmadi K. (2017) How to assess sustainability of suppliers in volume discount context? A new data envelopment analysis approach. Transportation Research. Part D: Transport and Environment, no 51, pp. 102-121. DOI: 10.1016/j.trd.2016.11.030.

17. Kalantary M., Saen R.F. (2019) Assessing sustainability of supply chains: An inverse network dynamic DEA model. Computers \& Industrial Engineering, no 135, pp. 1224-1238. DOI: 10.1016/j.cie.2018.11.009.

18. Khodakarami M., Shabani A., Saen R.F., Azadi M. (2015) Developing distinctive two-stage data envelopment analysis models: An application in evaluating the sustainability of supply chain management. Measurement, no 70, pp. 62-74. DOI: 10.1016/j.measurement.2015.03.024.

19. Mirhedayatian S.M., Azadi M., Saen R.F. (2014) A novel network data envelopment analysis model for evaluating green supply chain management. International Journal of Production Economics, no 147, pp. 544-554. DOI: 10.1016/j.ijpe.2013.02.009.

20. Sarah J., Khalili-Damghani K. (2019) Fuzzy type-II De-Novo programming for resource allocation and target setting in network data envelopment analysis: a natural gas supply chain. Expert Systems with Applications, no 117, pp. 312-329. DOI: 10.1016/j.eswa.2018.09.046.

21. Shafiee M., Lotfi F.H., Saleh H. (2014) Supply chain performance evaluation with data envelopment analysis and balanced scorecard approach. Applied Mathematical Modelling, vol. 38, no 21-22, pp. 5092-5112. DOI: 10.1016/j.apm.2014.03.023.

22. Tajbakhsh A., Hassini E. (2015) A data envelopment analysis approach to evaluate sustainability in supply chain networks. Journal of Cleaner Production, no 105, pp. 74-85. DOI: 10.1016/j.jclepro.2014.07.054.

23. Tavana M., Kaviani M.A., Di Caprio D., Rahpeyma B. (2016) A two-stage data envelopment analysis model for measuring performance in three-level supply chains. Measurement, no 78, pp. 322-333.

DOI: $10.1016 / j$.measurement.2015.10.023.

24. Tavana M., Mirzagoltabar H., Mirhedayatian S.M., Saen R.F., Azadi M. (2013) A new network epsilon-based DEA model for supply chain performance evaluation. Computers \& Industrial Engineering, vol. 66, no 2, pp. 501-513. DOI: 10.1016/j.cie.2013.07.016.

25. Tavassoli M., Saen R.F. (2019) Predicting group membership of sustainable suppliers via data envelopment analysis and discriminant analysis. Sustainable Production and Consumption, no 18, pp. 41-52. DOI: $10.1016 / j . s p c .2018 .12 .004$.

26. Yousefi S., Soltani R., Saen R.F., Pishvaee M.S. (2017) A robust fuzzy possibilistic programming for a new network GP-DEA model to evaluate sustainable supply chains. Journal of Cleaner Production, no 166, pp. 537-549. DOI: 10.1016/j.jclepro.2017.08.054. 
27. Zhai D., Shang J., Yang F., Ang S. (2019) Measuring energy supply chains' efficiency with emission trading: A two-stage frontier-shift data envelopment analysis. Journal of Cleaner Production, no 210, pp. 1462-1474. DOI: 10.1016/j.jclepro.2018.10.355.

28. Banker R.D., Charnes A., Cooper W.W. (1984) Some models for estimating technical and scale inefficiencies in data envelopment analysis. Management Science, vol. 30, no 9, pp. 1078-1092. DOI: 10.1287/mnsc.30.9.1078.

29. Cooper W.W., Seiford L., Tone K. (2002) Data envelopment analysis: A comprehensive text with models, applications, references and DEA-solver software. Norwell, Massachusetts, US: Kluwer Academic Publishers.

30. Cook W.D., Zhu J., Bi G., Yang F. (2010) Network DEA: Additive efficiency decomposition. European Journal of Operational Research, vol. 207, no 2, pp. 1122-1129. DOI: 10.1016/j.ejor.2010.05.006.

31. Cook W.D., Liang L., Zhu J. (2010) Measuring performance of two-stage network structures by DEA: A review and future perspective. Omega, vol. 38, no 6, pp. 423-430. DOI: 10.1016/j.omega.2009.12.001.

\section{Mehdi Shoja}

Ph.D. Student, Industrial Engineering Department, Roodehen Branch, Islamic Azad University, No 4, Shahid Ahmadi Alley, Valiasr Town, Firoozkooh, Tehran 3981838183, Iran;

E-mail: mmsh.bim@gmail.com

ORCID: 0000-0001-9221-8071

\section{Farhad Hosseinzadeh Lotfi}

Professor, Mathematics Department, Science and Research Branch, Islamic Azad University, Shohada Hesarak Blv, University Square, End of Shahid Sattari Highway, Tehran 1477893855, Iran;

E-mail: farhad@hosseinzadeh.ir

ORCID: 0000-0001-5022-553X

\section{Amir Gholam Abri}

Associate Professor, Mathematics Department, Firoozkooh Branch, Islamic Azad University, First of Valiasr Town, 45 Meters Street, Firoozkooh, Tehran 3981838381, Iran;

E-mail: amirgholamabri@gmail.com

ORCID: 0000-0003-1981-9756

\section{Alireza Rashidi Komijan}

Associate Professor, Industrial Engineering Department, Firoozkooh Branch, Islamic Azad University, First of Valiasr Town, 45 Meters Street, Firoozkooh, Tehran 3981838381, Iran;

E-mail: rashidi@azad.ac.ir

ORCID: 0000-0001-7705-980X 